\title{
Estimating escapement of fish and invertebrates in a Danish anchor seine
}

\author{
Noack, Thomas; Madsen, Niels; Mieske, Bernd; Frandsen, Rikke; Wieland, Kai; Krag, Ludvig Ahm
}

Published in:

ICES Journal of Marine Science

Link to article, DOI:

10.1093/icesjms/fsx066

Publication date:

2017

Document Version

Peer reviewed version

Link back to DTU Orbit

Citation (APA):

Noack, T., Madsen, N., Mieske, B., Frandsen, R., Wieland, K., \& Krag, L. A. (2017). Estimating escapement of fish and invertebrates in a Danish anchor seine. ICES Journal of Marine Science, 74(9), 2480-2488.

https://doi.org/10.1093/icesjms/fsx066

\section{General rights}

Copyright and moral rights for the publications made accessible in the public portal are retained by the authors and/or other copyright owners and it is a condition of accessing publications that users recognise and abide by the legal requirements associated with these rights.

- Users may download and print one copy of any publication from the public portal for the purpose of private study or research.

- You may not further distribute the material or use it for any profit-making activity or commercial gain

- You may freely distribute the URL identifying the publication in the public portal 


\section{Estimating escapement of fish and invertebrates}

\section{2 in a Danish anchor seine}

3 Thomas Noack $^{1 *}$, Niels Madsen ${ }^{1,2}$, Bernd Mieske $^{3}$, Rikke P. Frandsen ${ }^{1}$, Kai

$4 \quad$ Wieland ${ }^{1}$, Ludvig A. Krag ${ }^{1}$

${ }^{1}$ Technical University of Denmark, National Institute of Aquatic Resources, North Sea Science Park, PO Box 101, DK-9850 Hirtshals, Denmark

${ }^{2}$ Section of Biology and Environmental Science, Department of Chemistry and Bioscience, Aalborg University, Fredrik Bajers Vej 7, 9220 Aalborg, Denmark

$9 \quad{ }^{3}$ Thünen-Institute of Baltic Sea Fisheries, Alter Hafen Süd 2, 18069 Rostock, Germany

10 *Corresponding author: tel: +45358832 60; fax: +45 358832 60; email: thno@aqua.dtu.dk

\section{Abstract}

12 The codend is generally presumed to be the place where the main selectivity of fish occurs in towed 13 fishing gears, but other parts of the net have been found to contribute to the selectivity process of several 14 invertebrate species. This means that conventional selectivity or survival studies may ignore the 15 selectivity of net parts other than the codend for certain species. By attaching 12 small meshed collecting 16 bags to different parts of a Danish anchor seine net and conducting normal commercial fishing activities, 17 this study showed that there is a substantial escapement of fish and (especially) invertebrates from the 18 forward parts of the seine net. For seven species of demersal fish, most fish escaped through the lower 19 panel close to the codend. All invertebrate species were found in higher numbers in the collecting bags 20 than in the codend where many organisms escaped in the lower panel of the wings or the belly. Mean 21 levels of visible damage ranged from 1.00 to 3.25 for collected invertebrates and were similar for all gear 
22 parts. Common starfish (Asterias rubens), however, showed highest damage in the extension part of the 23 net.

24 Keywords: Damage index, Ecosystem effects, Sea bed impacts, Selectivity, Skagerrak, 25 Unaccounted mortality

\section{Introduction}

The codend is the part of towed fishing gears where the catch is collected and where the main selection of fish occurs (Wileman et al., 1996). Therefore, most studies on towed fishing gears, e.g., selectivity studies on trawls (e.g., Reeves et al., 1992; Graham et al., 2004; Frandsen et al., 2010) or Danish anchor seines (e.g., Herrmann et al., 2016; Noack et al., 2017), or survival studies (e.g., Bergmann and Moore, 2001; Uhlmann et al., 2016), focused on the individuals in or escaping from the codend. Previous studies on the selectivity of commercially valuable crustaceans in different types of trawls, however, found that a substantial part of the selection of Norway lobster (Nephrops norvegicus; Hillis and Earley, 1982), brown shrimp (Crangon crangon; Polet, 2000) and Antarctic krill (Euphausia superba; Krag et al., 2014a) takes place in the forward parts of a trawl net. It may be expected that other invertebrates (Wileman et al., 1996) and possibly some fish species show similar patterns in towed fishing gears. Such trawl-body selectivity cannot be seen and is not considered in studies that are limited to the codend. Therefore, the magnitude of such escape and the potential damage to individuals caused by interactions with the fishing gear remain unaccounted for in standard selectivity and survival studies.

There is an increased focus on expanding the understanding of how various types of fishing affect the marine ecosystem during their deployment (Fulton et al., 2014). This highlights the need to gather information on different fishing methods, including Danish anchor seining which is considered to be a fuel-efficient fishing method (Thrane, 2004; Suuronen et al., 2012; Walsh and Winger, 2011) with low environmental impacts compared to other demersal fishing gears (Suuronen et al., 2012; Eigaard et al., 2016; Walsh and Winger, 2011) that delivers high quality catches (Dreyer et al., 2008; Suuronen et al., 2012; Walsh and Winger, 2011). One example of integrating the ecosystem effects of different 
47 fishing gears into management strategies is the current EU Common Fisheries Policy (Zhou et al., 2010)

48 which aims at assessing and reducing potential negative impacts from fishing gears on the marine habitat.

49 An assessment of unaccounted selectivity is therefore important, particularly if these unobserved 50 interactions can lead to unaccounted mortality.

51 The escape of animals from a Danish seine may vary in numbers, sizes and between species in 52 the different gear parts, e.g., because the fishing process is partly asymmetrical and the numbers of 53 animals entering each side of the gear are likely to be different (Wileman et al., 1996). To account for 54 this in this study, the net of a Danish seine was divided into different parts which were strategically 55 covered with small mesh bags. Previous studies on trawls demonstrated successfully that small mesh 56 bags or pocket meshes can be used to estimate escapement of fish and invertebrates from gear parts other 57 than the codend (Hillis and Earley, 1982; Nakashima, 1990; Dremiere et al., 1999; Williams et al., 2011;

58 Suuronen et al., 1997). This setup was used under the commercial conditions of Danish seining in Danish 59 waters to collect escaping fish and invertebrates throughout the gear. To quantify the effects of net 60 interaction and escape on the collected animals, damage was assessed for all caught invertebrates. This 61 served as a measure to indicate potential mortality and to compare selectivity and damage in the different 62 parts of the seine net.

\section{Material and Methods}

\section{$64 \quad$ Study site and experimental setup}

65

66

67

68

69

70

Experimental fishing was carried out with the commercial Danish seiner HG 35 Vendelbo (length overall: $15.47 \mathrm{~m}$, engine power: $91 \mathrm{~kW}$ ) in August and September 2014. All hauls were carried out off the coast of Denmark in Skagerrak (ICES area IIIa; Figure 1). As commercial Danish seining is not only conducted on sandy flatfish areas close to the coast (e.g., for plaice Pleuronectes platessa), but also on deeper whitefish grounds (e.g., for haddock Melanogrammus aeglefinus and cod Gadus morhua), this study was conducted in both area types (Figure 1). 
72 to different parts of the vessel's seine net (for vessel and gear specifications, see Noack et al. (2017)).

73 Each collecting bag was $4.8 \mathrm{~m}$ long (stretched) and covered $\sim 0.5 \mathrm{~m}^{2}$ of the seine netting (55 - 121

74 meshes, depending on mesh size and mesh configuration of the specific net part). As the global geometry

75 of a Danish seine changes considerably during the fishing process, we expected the netting characteristics

76 of the different net parts to do the same. Due to the size of the seine net, such effects could not be

77 experimentally tested in a flume tank. The collecting bags were therefore mounted with the aim of

78 covering the same area of netting without distorting the seine during any stages of the fishing process.

79 Collecting bags that were attached to the wings (bags 1-8) were not modified with weight or floats as a

80 sufficient opening of those was expected to be achieved by the angle of the wings in relation to the

81 towing direction. The collecting bags that were attached to the belly and the extension part of the net

82 were expected to potentially mask the netting of the seine part they covered. To account for this, the two

83 collecting bags in the upper panel of belly and extension (bags 9 and 11, Figure 2C) were equipped with

84 four floats and a lead rope was attached to the two collecting bags in the lower panel (bags 10 and 12 ,

85 Figure 2D) to prevent masking. To assess their performance, two underwater video cameras (GoPro Hero

$863^{+}$) without artificial light were attached close to collecting bag 9 in the upper panel and collecting bag

$87 \quad 10$ in the lower panel during hauls 1 and 7.

88

\section{Data collection and sampling strategy}

Fishing time, anchor depth and depth at the position where the net was deployed were recorded as well as sea state following the protocol of Wileman et al. (1996). Vessel movement during the fishing process was tracked for each haul, using a GPS-logger (Canmore G-PORTER GP-102+). After each haul, fish and invertebrates were separated, fish were measured to the nearest $\mathrm{cm}$ below and individual weights were estimated using length weight relationships (Coull et al., 1989). All invertebrates were frozen until treated further on land where they were identified, counted, length measured to nearest $\mathrm{mm}$ and weight measured to nearest mg. Length measurements differed from species to species, based on 
96 their body shape (see Table 1 for details). Additionally, a damage index based on Veale et al. (2001) was

97 applied to each individual, whereby levels depended on individual species characteristics (Table 1). The

98 lowest level of damage for sessile organisms (Porifera and Anthozoa) was set to "Level 3", because

99 detaching sessile organisms from their substrate was also considered a damage which reduced their

100 chance of surviving the interaction with the fishing gear. Due to large codend catches, catches of plaice

101 were subsampled within the first three hauls (range of subsampling factor: $0.07-0.70$ ) following the

102 guidelines of Gerritsen and McGrath (2007).

103 Data analysis

104

105

106

107

108

109

110

111

112

113

114

115

116

117

118

119 (significance level $\alpha \leq 0.05$ ). (significance level $\alpha \leq 0.05$ ).

After providing individual haul information, hauls from the two area types were pooled to provide a combined picture for the areas where Danish seiners fish commercially. The seven hauls conducted did not allow for separate analyses between the two areas as numbers of individuals caught in the collecting bags were relatively low. Numbers of individuals in the collecting bags were raised to a value indicating how many individuals passed through the netting of the respective part of the gear using a raising factor (number of meshes covered by bag/number of meshes in gear part) ranging from 0.01 to 0.07 . Graphical catch distributions of fish and invertebrates were made based on raised values showing both absolute and relative catch numbers in the collecting bags. Besides numbers of individuals, average sizes (mean \pm standard deviation) of the animals observed in the collecting bags are given. Due to low numbers of individuals per single bag, values were pooled for the "upper collecting bags" (collecting bags $1,3,5,7,9,11$ ) and the "lower collecting bags" (collecting bags 2, 4, 6, 8, 10, 12). Hermit crabs (Pagurus spp.), which lost their shell, as well as sea stars without any arms were excluded from this part of the analysis as a proper length measurement was not possible for those. A one-way analysis of variance (ANOVA) with gear part as fixed factor followed by a Tukey-HSD test was used to test for significant differences between mean length of the caught organisms in the different gear parts 
121 compared between the gear parts. This part was restricted to species observed in at least two different 122 gear parts. A one-way analysis of variance (ANOVA) with gear part as fixed factor followed by a Tukey123 HSD test was used for each species to test for significant differences between damage levels in the 124 different gear parts (significance level $\alpha \leq 0.05$ ).

125 All analyses were done using R Statistical Software (Core Team, 2012).

126 Results

127 Haul overview

Seven valid hauls with durations ranging from 131 to $180 \mathrm{~min}$ were conducted (Table 2). The hauls were carried out in depths between 12.8 and $73.2 \mathrm{~m}$ and covered an area ranging from 2.6 to 3.5 $\mathrm{km}^{2}$. Codend catches ranged from 94 to $2172 \mathrm{~kg}$ per haul. The sum of catches in the collecting bags ranged from 0.5 to $2.4 \mathrm{~kg}$ per haul. Inspection of underwater recordings showed that the floats attached to the collecting bags in the upper panel and lead lines attached to the collecting bags in the lower panel worked as intended as the bags did not mask the meshes of the seine net (Figure 3).

\section{Catches of fish}

A higher diversity of fish species was observed in the codend than in the collecting bags (bags: 14 species, codend: 21 species, total: 26 species) and nine species were observed in both codend and at least one of the collecting bags (cod, dab Limanda limanda, flathead grey mullet Mugil cephalus, grey gurnard Eutrigla gurnardus, lemon sole Microstomus kitt, plaice, red gurnard Chelidonichthys cuculus, sole Solea solea and whiting Merlangius merlangus (Table 3)). For all of them, except for plaice and red gurnard, the number of fish in the codend was lower than the sum of the raised numbers in the collecting

141 bags (Table 3). The number of individuals escaping through meshes in the wings was very low but 142 increased towards the codend (Table 3). As also shown in Figure 4, the number of individuals was considerably higher in bags from the lower panel. Only herring (Clupea harengus), sprat (Sprattus 
144 sprattus) and whiting escaped to a large extent through the upper panel in the aft part of the seine net.

145 Differences in the horizontal plane were minor (Table 3, Figure 4). In the cases of dab and plaice, 146 individuals in the upper bags were significantly larger than in the lower bags (Table 3).

\section{Catches of invertebrates}

Twelve of twenty invertebrate species caught were found in the collecting bags and 15 species were found in the codend (Table 3). For species that were observed in both codend and at least one collecting bag (common starfish Asterias rubens, common whelk Buccinum undatum, hermit crabs, red whelk Neptunea antiqua, sand star Astropecten irregularis, sandy swimming crab Liocarcinus depurator, sponges Porifera spp.), the sum of raised numbers from the collecting bags was higher than the number of individuals observed in the codend (Table 4). Numbers in the collecting bags of the lower wings and the lower aft part of the gear were similar, but only two organisms were observed in the bags

of the upper panel (Table 4). More individuals were found in the collecting bags of the portside wing than in bags of the starboard wing (Table 4, Figure 5). For both species that were observed in lower and upper bags (brown shrimp, common starfish), average length was significantly higher for individuals in the upper bags (Table 4).

\section{Damage index}

Means of the estimated levels of damage ranged from 1.00 to 3.25 , but were generally low for the inspected species (Table 5). Values of 2.00 were exceeded only by common starfish in the extension, by sand stars in the codend and by sponges in the inner wings and the codend (Table 5). Comparing damage indices of invertebrates was limited by the issue of unequally distributed species, allowing the comparison for only nine species (brown shrimp, common starfish, common whelk, hermit crab, purple heart sea urchin Spatangus purpureus, red whelk, sand star, sandy swimming crab, sponges; Table 5). Differences between the gear parts were small and significant differences were only found for common starfish having significantly higher damage levels in the extension bags than in outer wing bags and belly bags (Table 5). 


\section{Discussion}

The results of this study clearly showed that fish and especially invertebrates interact with, and escape from, most parts of a commercial Danish anchor seine during the fishing operation. The majority of invertebrates were caught in the collecting bags mounted to the lower panel of the seine net, whereas the relatively few caught fish were primarily found in the collecting bags close to the codend. The part of the selection in gear parts other than the codend is substantial and is currently not accounted for in conventional selectivity studies that are based on codend catches. Paired or alternate haul techniques (Wileman et al., 1996) could potentially show this effect, but would not be able to describe in which part of the seine net the selectivity occurred.

As has also been shown by previous studies (Hillis and Earley, 1982; Dremiere et al., 1999; Williams et al., 2011; Suuronen et al., 1997; Nakashima, 1990), collecting bags provide a suitable option to investigate escapement of animals from gear parts of mobile fishing gears where conventional techniques like covers are not possible to be used. However, it is important to treat the estimated numbers of escapees with care. Although the collecting bags were distributed over the entire commercial seine net, to indicate each parts' selectivity, they only covered a small fraction (3-15\%) of the part they were mounted to. In addition, there were generally low amounts of individuals in the study area, which probably explains the relatively low numbers in the collecting bags. Furthermore, our resulting pooling of the data may have masked any potential area effect. More or larger small meshed collecting bags on the seine net were considered to increase the risk of affecting the commercial operation of the seine net due to extra drag. As twine characteristics, mesh sizes, mesh openings and thus the potential selectivity vary between different parts in the seine net, so does the catch in the different collection bags. The catches in the collecting bags might also be affected by considerable changes in the entire net geometry during the fishing process, starting with a loose net in the beginning that goes over a period of being overspread (high horizontal opening, low vertical opening) to a completely closed phase in the final stages of the retrieval process. Based on the conducted underwater observations, this did, however, not seem to affect the operation of the observed collecting bags. 

capelin in midwater trawls (Nakashima, 1990) and other species in bottom trawls (Dremiere et al., 1999). Demersal species escaped preferentially through the lower panel, where pelagic species like herring and sprat escaped solely through meshes in the upper panel in the aft part of the gear. Preferences of pelagic fish to escape upwards were also made by a study that investigated escapement in bottom trawls (Dremiere et al., 1999) and a study that described the behavior of herring in relation to midwater trawls (Suuronen et al., 1997). Such species specific behavioral differences can be used to improve the seine net's species or size selectivity as demonstrated for trawls (Thomsen, 1993; Krag et al., 2014b; Krag et al., 2015).

Contrary to fish, invertebrates have limited motility. Where fish swim and actively orientate in relation to the surrounding netting to avoid contact with it (Glass et al., 1993; Glass and Wardle, 1995), invertebrates are expected to roll more passively along the lower netting resulting in multiple contacts with the meshes from the net mouth and back towards the codend. The catches of invertebrates in the collecting bags indicated that most invertebrates escaped through the netting in the lower forward sections of the seine net and that only a small proportion of the invertebrates that entered the seine net ended up in the codend. High numbers of invertebrates escaping from gear parts other than the codend were observed for bottom trawls (Hillis and Earley, 1982; Dremiere et al., 1999). The general selectivity pattern for invertebrates in seine nets and trawls, is therefore different from fish that primarily escape through meshes in the codend (Wileman et al., 1996). This difference between fish and invertebrates can

214 be utilized to reduce catches of unwanted invertebrates without losing fish as fish avoid contact with the 215 forward netting parts (Glass et al., 1993; Glass and Wardle, 1995). In the North Sea, for instance, benthic release panels mounted to the lower netting of beam trawls were found to successfully reduce catches of unwanted invertebrates (Revill and Jennings, 2005).

As the present study showed, codend selectivity does not reflect the entire selectivity process for 219 invertebrates in Danish seines. Quantifying the escape of invertebrates in Danish seines or trawls, as part 220 of a comprehensive description of active gears' interactions with the ecosystem, will require approaches 
221 similar to the current approach. The system of collecting bags makes such quantifications possible and

222 further appeared relatively sensitive to pick up small differences between net parts. For instance, higher

223 escape rates of invertebrates in the portside than in the starboard side of the seine net could be indicated.

224 Due to the asymmetrical way the Danish seine is set out and dragged in the early stages of the fishing

225 process (Wileman et al., 1996), these differences were expected. Contrary to invertebrates, this 226 asymmetrical catch tendency was not observed for fish as fish actively avoid the netting (Glass et al., 227 1993).

The assessment of the invertebrates' damage indicated relatively low levels of visual damage, 229 which is likely due to their robust exoskeleton or shells. Similar results have been found for trawls 230 (Bergmann et al., 2001). Higher levels of damage in aft parts than in front parts, which were observed 231 for common starfish, indicated that a longer time and distance inside the netting results in more 232 mechanical interaction with the netting. This means that lower damage levels can be expected if such 233 animals could be released earlier in the process. The commercial seine net used in the current study had 234 relative large meshes in the forward sections of the seine net $(120-160 \mathrm{~mm})$ which presumably resulted 235 in already high numbers of escapees. In smaller mesh designs, it would be expected that the organisms 236 require a higher contact probability with the netting to successfully escape, if physically possible. Such 237 designs, which can be found in the Nephrops directed trawl designs (Krag et al., 2008) may result in an 238 increase of mechanical damages due to the increased netting contact and longer towing durations. 239 However, the damage assessment in the current study considered only visible external damages and 240 conclusions of previous studies about relationships of external damages and mortality are inconsistent 241 (Broadhurst et al., 2006). Therefore, the degree of damage cannot be translated directly into mortality 242 rates and future experiments should include survival assessments and evaluate mechanical as well as 243 physiological damage as a proxy for survival. If it is concluded that low survival is the consequence of 244 organisms ' interaction with seines or trawls, then there is a need to develop invertebrate release systems 245 similar to the benthic release panels used in some beam-trawl fisheries (Revill and Jennings, 2005). By 
246 applying the findings of the present study, these devices should be implemented into the front part of the 247 gear.

\section{Supplementary material}

The following supplementary material is available at ICESJMS online: Supplementary Table S1 which provides a full catch overview of all observed fish species.

251

252

253

254

255

256

257

\section{Acknowledgement}

The authors thank the crew of HG 35 Vendelbo, netmaker Ray Godtliebsen, Gert Holst and Reinhardt Jensen and other technicians from DTU Aqua's monitoring section in Hirtshals, being indispensable in preparing, conducting and follow-up work of the sea trials. Comments to content and language by Javed Khan are greatly acknowledged. The study was carried out as a part of the Skånfisk project with financial support of the Ministry of Environment and Food of Denmark.

\section{References}

Bergmann, M., Beare, D. J., Moore, P. G. 2001. Damage sustained by epibenthic invertebrates discarded in the Nephrops fishery of the Clyde Sea area, Scotland. Journal of Sea Research, 45: $105-118$.

Bergmann, M., Moore, P. G. 2001. Survival of decapod crustaceans discarded in the Nephrops fishery of the Clyde Sea area, Scotland. ICES Journal of Marine Science, 58: 163-171.

Broadhurst, M. K., Suuronen, P., Hulme, A. 2006. Estimating collateral mortality from towed fishing gear. Fish and Fisheries, 7: 180-218.

Coull, K. A., Jermyn, A. S., Newton, A. W., Henderson, G. I., Hall, W. B. 1989. Length/Weight Relationships for 88 species of Fish Encountered in the North East Atlantic. Scottish Fisheries Research Report 43. 81 pp. 
Dremiere, P.-Y., Fiorentini, L., Cosimi, G., Leonori, I., Sala, A., Spagnolo, A. 1999. Escapement from the main body of the bottom trawl used for the Mediterranean international trawl survey (MEDITS). Aquatic Living Resources, 12: 207-217.

Dreyer, B. M., Nøstvold, B. H., Midling, K. Ø., Hermansen, Ø. 2008. Capture-basedaquaculture of cod. In: Lovatelli, A., Holthus, P.F. (Eds), Capture-based aquaculture. Global overview. FAO Fisheries Technical Paper No. 508. pp. 183-198.

Eigaard, O. R., Bastardie, F., Breen, M., Dinesen, G. E., Hintzen, N. T., Laffargue, P., Mortensen, L. O., et al. 2016. Estimating seabed pressure from demersal trawls, seines, and dredges based on gear design and dimensions. ICES Journal of Marine Science, 73: i27-i43.

Frandsen, R. P., Madsen, N., Krag, L. A. 2010. Selectivity and escapement behaviour of five commercial fishery species in standard square- and diamond-mesh codends. ICES Journal of Marine Science, 67: 1721-1731.

Fulton, E. A., Smith, A. D. M., Smith, D. C., Johnson, P. 2014. An integrated approach is needed for ecosystem based fisheries management: Insights from ecosystem-level management strategy evaluation. PLOS ONE, 9: e84242.

Gerritsen, H. D., McGrath, D. 2007. Precision estimates and suggested sample sizes for lengthfrequency data. Fishery bulletin, 105: 116-120.

Glass, C. W., Wardle, C. S. 1995. Studies on the use of visual stimuli to control fish escape from codends. II. The effect of a black tunnel on the reaction behaviour of fish in otter trawl codends. Fisheries Research, 23: 165-174.

Glass, C. W., Wardle, C. S., Gosden, S. J. 1993. Behavioural studies of the principles underlying mesh penetration by fish. ICES Marine Science Symposia, 196: 92-97.

Graham, N., O’Neill, F. G., Fryer, R. J., Galbraith, R. D., Myklebust, A. 2004. Selectivity of a 120 mm diamond cod-end and the effect of inserting a rigid grid or a square mesh panel. Fisheries Research, 67: 151-161. 
Herrmann, B., Krag, L. A., Feekings, J., Noack, T. 2016. Understanding and predicting size selection in diamond-mesh cod ends for Danish seining: A study based on sea trials and computer simulations. Marine and Coastal Fisheries, 8: 277-291.

Hillis, J., Earley, J. 1982. Selectivity in the Nephrops trawl. ICES C. M. 1982/B19: 1-11.

Krag, L. A., Frandsen, R. P., Madsen, N. 2008. Evaluation of a simple means to reduce discard in the Kattegat-Skagerrak Nephrops (Nephrops norvegicus) fishery: Commercial testing of different codends and square-mesh panels. Fisheries Research, 91: 175-186.

Krag, L. A., Herrmann, B., Iversen, S. A., Engås, A., Nordrum, S., Krafft, B. A. 2014a. Size selection of Antarctic krill (Euphausia superba) in trawls. PLOS ONE, 9: e102168.

Krag, L. A., Herrmann, B., Karlsen, J. D. 2014b. Inferring fish escape behaviour in trawls based on catch comparison data: Model development and evaluation based on data from Skagerrak, Denmark. PLoS ONE, 9: e88819.

Krag, L. A., Herrmann, B., Karlsen, J. D., Mieske, B. 2015. Species selectivity in different sized topless trawl designs: Does size matter? Fisheries Research, 172: 243-249.

Nakashima, B. S. 1990. Escapement from a Diamond IX midwater trawl during acoustic surveys for capelin (Mallotus villosus) in the Northwest Atlantic. ICES Journal of Marine Science ICES Journal of Marine Science, 47: 76-82.

Noack, T., Frandsen, R. P., Krag, L. A., Mieske, B., Madsen, N. 2017. Codend selectivity in a commercial Danish anchor seine. Fisheries Research, 186, Part 1: 283-291.

Polet, H. 2000. Codend and whole trawl selectivity of a shrimp beam trawl used in the North Sea. Fisheries Research, 48: 167-183.

Reeves, S. A., Armstrong, D. W., Fryer, R. J., Coull, K. A. 1992. The effects of mesh size, cod-end extension length and cod-end diameter on the selectivity of Scottish trawls and seines. ICES Journal of Marine Science, 49: 279-288.

Revill, A. S., Jennings, S. 2005. The capacity of benthos release panels to reduce the impacts of beam trawls on benthic communities. Fisheries Research, 75: 73-85. 
Suuronen, P., Chopin, F., Glass, C., Løkkeborg, S., Matsushita, Y., Queirolo, D., Rihan, D. 2012. Low impact and fuel efficient fishing - Looking beyond the horizon. Fisheries Research, 119-120: 135-146.

Suuronen, P., Lehtonen, E., Wallace, J. 1997. Avoidance and escape behaviour by herring encountering midwater trawls. Fisheries Research, 29: 13-24.

Thomsen, B. 1993. Selective flatfish trawling. ICES Marine Science Symposia, 196: 161-164.

Thrane, M. 2004. Energy consumption in the Danish fishery: Identification of key factors. Journal of Industrial Ecology, 8: 223-239.

Uhlmann, S. S., Theunynck, R., Ampe, B., Desender, M., Soetaert, M., Depestele, J. 2016. Injury, reflex impairment, and survival of beam-trawled flatfish. ICES Journal of Marine Science, 73: $1244-1254$.

Veale, L. O., Hill, A. S., Hawkins, S. J., Brand, A. R. 2001. Distribution and damage to the by-catch assemblages of the northern Irish Sea scallop dredge fisheries. Journal of the Marine Biological Association of the United Kingdom, 81: 85-96.

Walsh, S. J., Winger, P. D. 2011. Bottom seining in Canada, 1948-2010: Its development, fisheries and ecosystem impacts. Canadian technical report of fisheries and aquatic sciences No. 2922. 147 pp.

Wileman, D. A., Ferro, R. S. T., Fonteyne, R., Millar, R. B. 1996. Manual of methods of measuring the selectivity of towed fishing gears. ICES Coop. Res. Rep., No. 215. ICES, Copenhagen. 216 pp.

Williams, K., Punt, A. E., Wilson, C. D., Horne, J. K. 2011. Length-selective retention of walleye pollock, Theragra chalcogramma, by midwater trawls. ICES Journal of Marine Science, 68: 119-129.

Zhou, S., Smith, A. D. M., Punt, A. E., Richardson, A. J., Gibbs, M., Fulton, E. A., Pascoe, S., et al. 2010. Ecosystem-based fisheries management requires a change to the selective fishing philosophy. Proceedings of the National Academy of Sciences, 107: 9485-9489. 


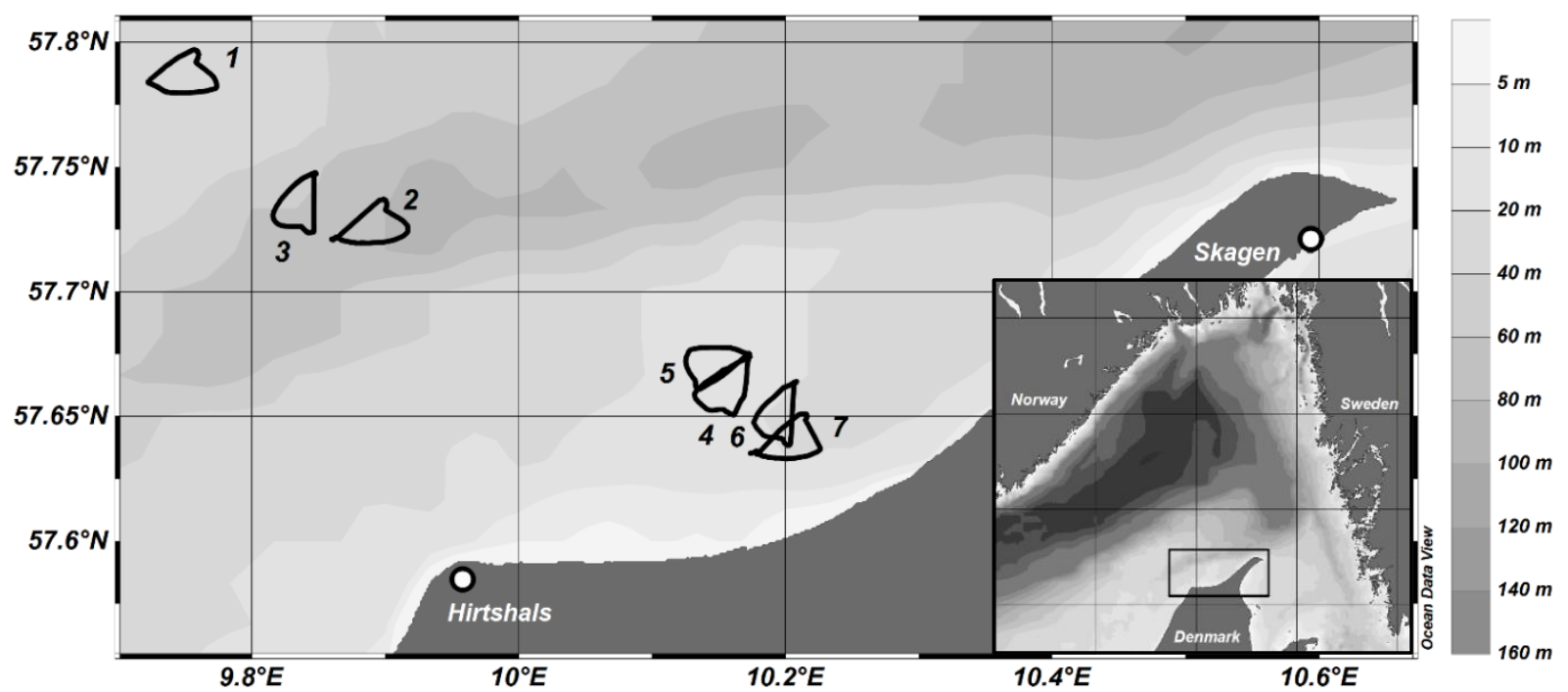

Figure 1. Area and vessel tracks for the seven hauls conducted on board the HG 35 Vendelbo in 2014.

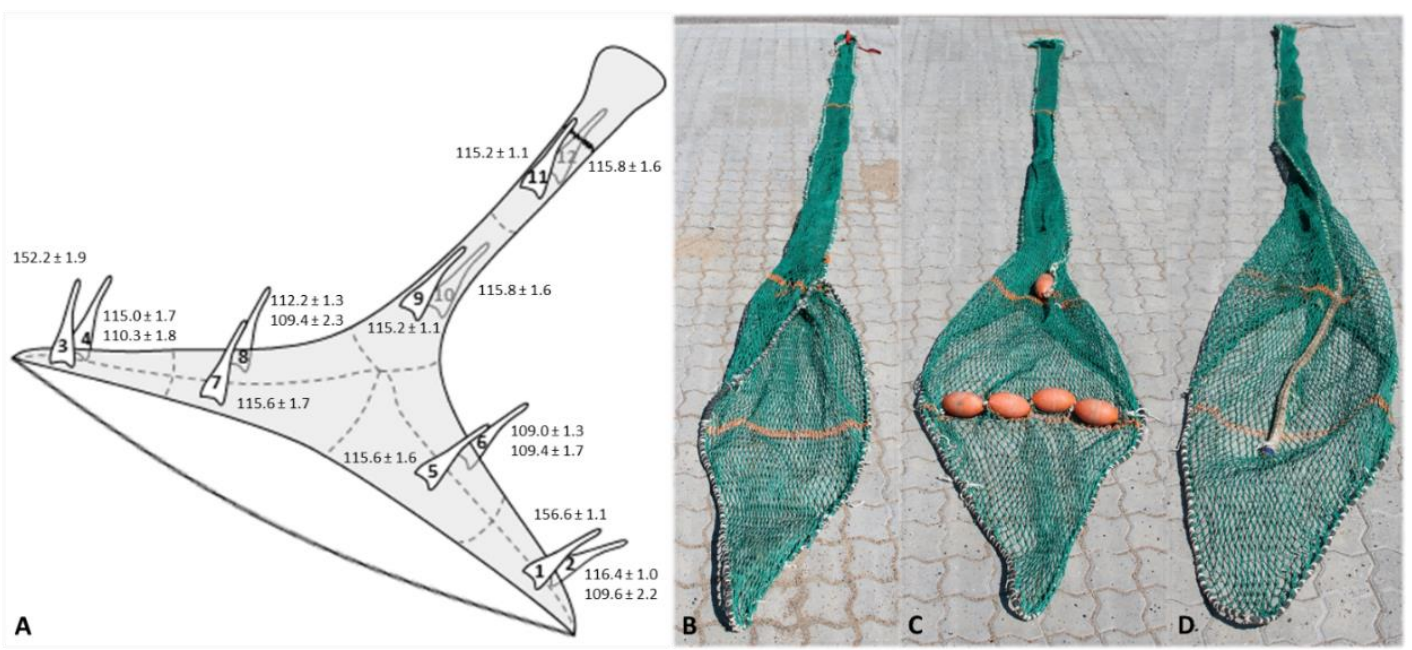

Figure 2. Collecting bags. A. Approximate locations, where bags were attached to seine net including mesh size in $\mathrm{mm}$ of the netting that was covered by the collecting bag ( \pm standard deviation). B. Standard bag (1-8). C. Upper bag with additional floats $(9+11)$. D. Lower bag with additional lead-filled rope $(10+12)$. 


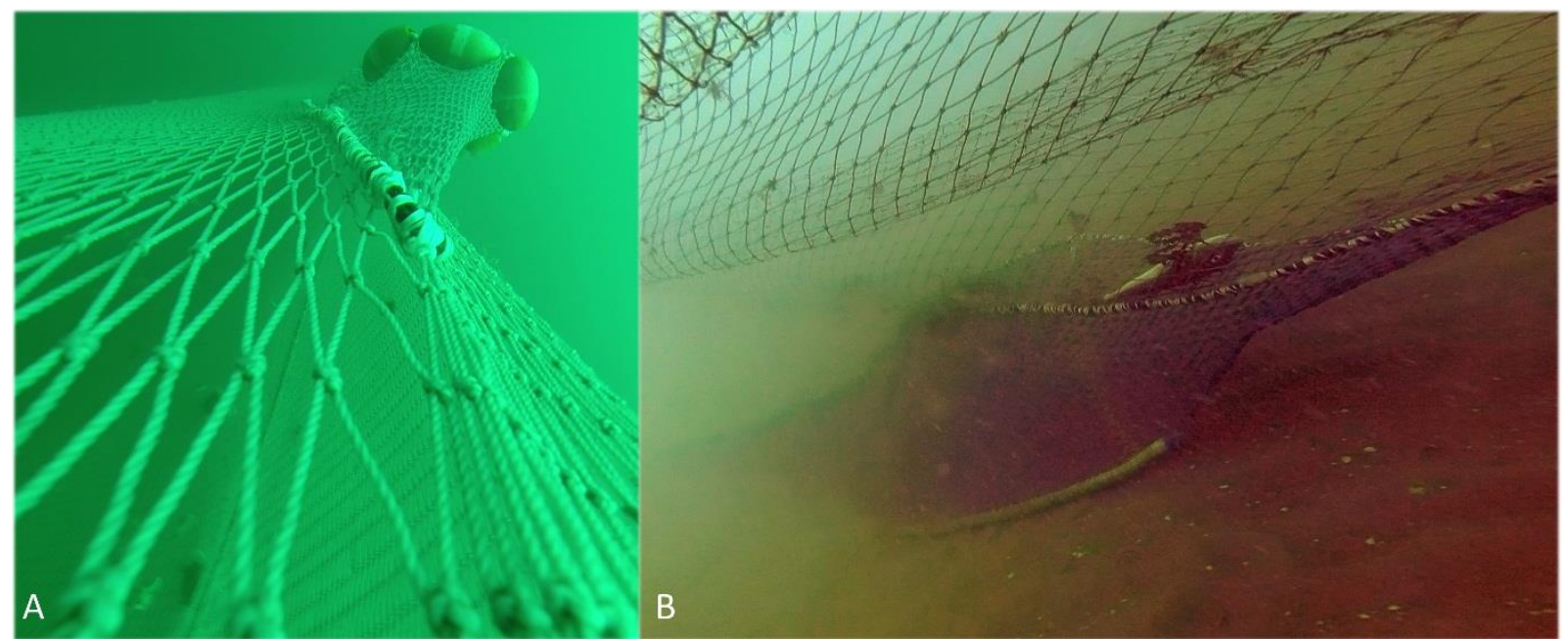

Figure 3. Examples of underwater observations, here collecting bags 9 (A; taken in final phase of haul 1) and 10 (B; taken in Haul 7 shortly before vessel returned to the anchor) showing that floats and lead rope functioned well in order to keep bags opened.

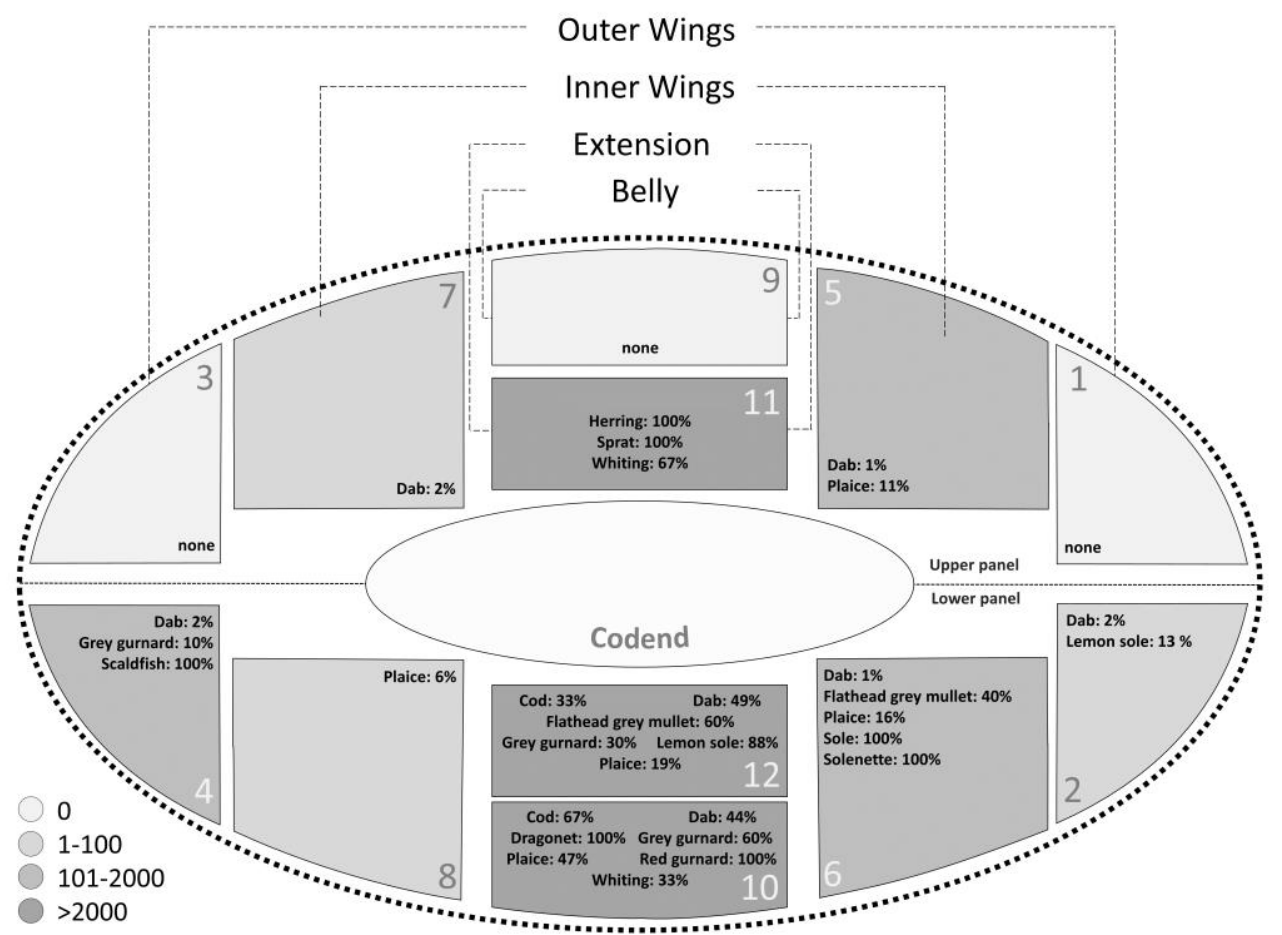

361 Figure 4. Raised individual numbers of fish species separated by gear part. Number in fields represents bag number, shade indicates absolute total number of individuals in the specific bag and percentage value indicates relative frequency of each species in all collecting bags. 


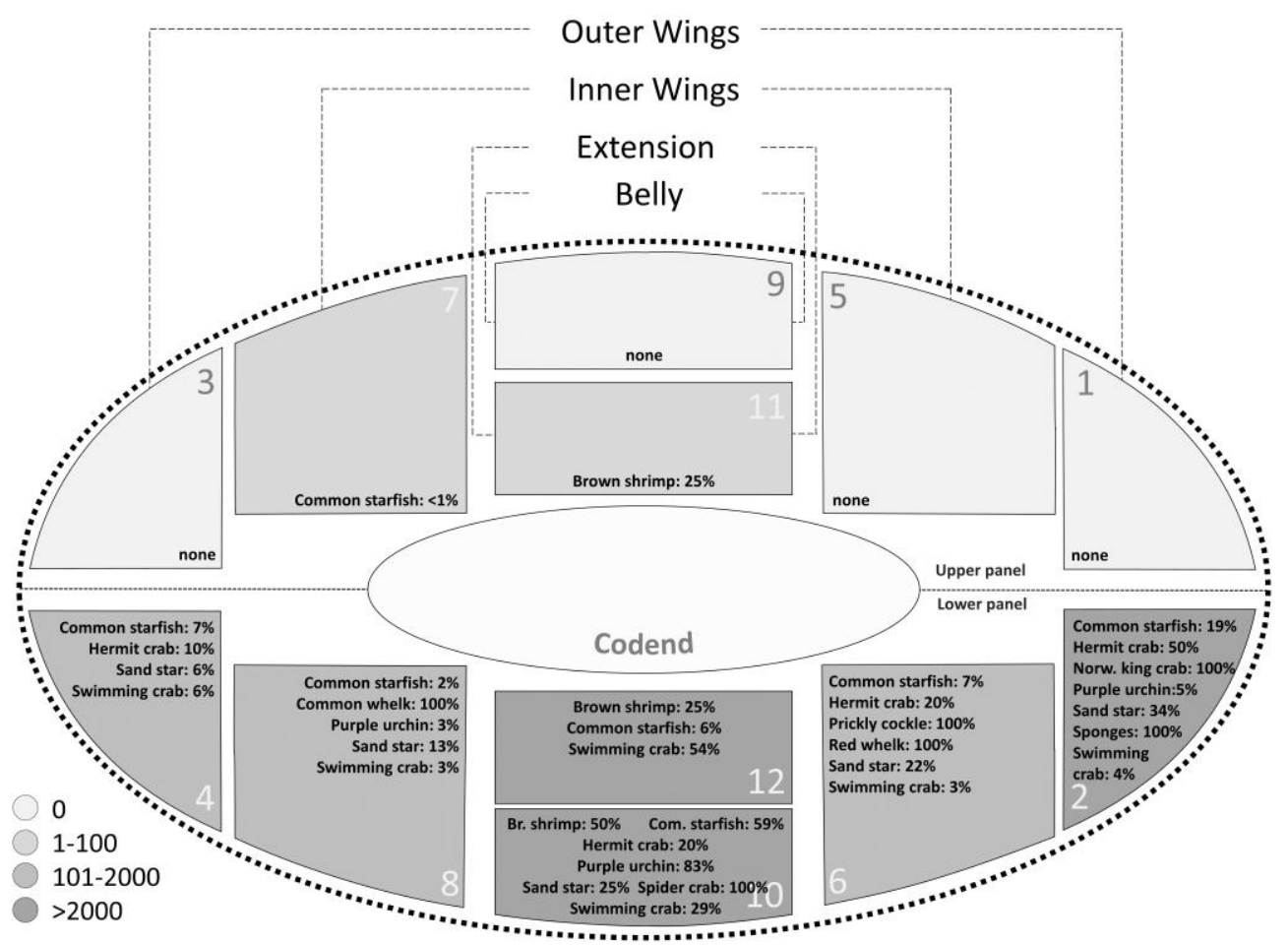

367 Figure 5. Raised individual numbers of invertebrate species separated by gear part. Number in fields 368 represents bag number, shade indicates absolute total number of individuals in the specific bag and 369 percentage value indicates relative frequency of each species in all collecting bags. 


\section{Tables}

2 Table 1. Length key and damage key (modified from Veale et al. (2001); the higher the more damage) for invertebrate species, ordered by taxonomic class.

\begin{tabular}{|c|c|c|c|c|c|c|c|}
\hline \multirow{2}{*}{ Class } & \multirow{2}{*}{ Species } & \multirow{2}{*}{ Length measurement } & \multicolumn{5}{|c|}{ Damage index } \\
\hline & & & 1 & 2 & 3 & 4 & 5 \\
\hline \multirow[t]{3}{*}{ Asteroidea } & Common starfish (Asterias rubens) & maximum extent & no visible damage & $-1 \mathrm{arm}$ & -2 arms & -3 to -4 arms & no arms \\
\hline & Sand star (Astropecten irregularis) & maximum extent & no visible damage & -1 arm & -2 arms & -3 to -4 arms & no arms \\
\hline & Spiny starfish (Marthasterias glacialis) & maximum extent & no visible damage & -1 arm & -2 arms & -3 to -4 arms & no arms \\
\hline \multirow[t]{6}{*}{ Malacostraca } & Edible crab (Cancer pagurus) & carapace width & no visible damage & -1 to -2 legs & -3 to -4 legs & -5 or more legs & broken carapax \\
\hline & Brown shrimp (Crangon crangon) & carapace length & no visible damage & -1 to -2 legs & -3 to -4 legs & -5 or more legs & broken carapax \\
\hline & Sandy swimming crab (Liocarcinus depurator) & carapace width & no visible damage & -1 to -2 legs & -3 to -4 legs & -5 or more legs & broken carapax \\
\hline & Norway king crab (Lithodes maja) & carapace length & no visible damage & -1 to -2 legs & -3 to -4 legs & -5 or more legs & broken carapax \\
\hline & Common spider crab (Macropodia rostrata) & carapace length & no visible damage & -1 to -2 legs & -3 to -4 legs & -5 or more legs & broken carapax \\
\hline & Hermit crabs (Pagurus spp.) & maximum shell extent & no visible damage & gentle & out of shell, intact & out of shell, not intact & broken carapax \\
\hline \multirow[t]{3}{*}{ Bivalvia } & Prickly cockle (Acanthocardia echinata) & maximum extent & no visible damage & gentle & medium & strong & irreparabel \\
\hline & Horse mussel (Modiolus modiolus) & maximum extent & no visible damage & gentle & medium & strong & irreparabel \\
\hline & Queen scallop (Aequipecten opercularis) & maximum extent & no visible damage & gentle & medium & strong & irreparabel \\
\hline \multirow[t]{2}{*}{ Gastropoda } & Common whelk (Buccinum undatum) & maximum extent & no visible damage & gentle & medium & strong & irreparabel \\
\hline & Red whelk (Neptunea antiqua) & maximum extent & no visible damage & gentle & medium & strong & irreparabel \\
\hline \multirow[t]{6}{*}{ Other } & Purple heart urchin (Spatangus purpureus) & maximum extent & no visible damage & gentle & medium & strong & irreparabel \\
\hline & Sea mouse (Aphrodite aculeata) & maximum extent & no visible damage & gentle & medium & strong & irreparabel \\
\hline & European squid (Loligo vulgaris) & maximum extent & no visible damage & gentle & medium & strong & irreparabel \\
\hline & Crevice brittlestar (Ophiopholis aculeata) & maximum extent & no visible damage & -1 arm & -2 arms & -3 to -4 arms & no arms \\
\hline & Sponges (Porifera) & maximum extent & - & - & no visible damage & medium & strong \\
\hline & Sea anemones (Actinaria spp.) & maximum extent & - & - & no visible damage & medium & strong \\
\hline
\end{tabular}


1 Table 2. Haul overview. Duration describes time from setting anchor until gear is retrieved onboard. 2 Depth is given for position where anchor was set and where the seine was deployed. Sea state after 3 Wileman et al. (1996).

\begin{tabular}{ccccccccc}
\hline \multirow{2}{*}{ Haul } & \multirow{2}{*}{ Date } & \multirow{2}{*}{$\begin{array}{c}\text { Duration } \\
(\mathrm{min})\end{array}$} & \multirow{2}{*}{$\begin{array}{c}\text { Covered area } \\
\left(\mathrm{km}^{2}\right)\end{array}$} & \multicolumn{2}{c}{ Depth $(\mathrm{m})$} & & \multicolumn{2}{c}{ Total catch $(\mathrm{kg})$} \\
& & & & Anchor & Seine & & Codend & Collecting bags \\
\hline 1 & 23.08 .2014 & 145 & 3.44 & 32.9 & 34.7 & 5 & 576.4 & 0.5 \\
2 & 26.08 .2014 & 151 & 3.42 & 69.5 & 73.2 & 2 & 2172.4 & 0.5 \\
3 & 26.08 .2014 & 135 & 3.17 & 42.1 & 54.9 & 2 & 860.1 & 2.4 \\
4 & 27.08 .2014 & 166 & 3.52 & 15.2 & 15.2 & 3 & 135.2 & 1.0 \\
5 & 27.08 .2014 & 160 & 3.13 & 15.2 & 15.7 & 2 & 94.1 & 0.5 \\
6 & 27.08 .2014 & 131 & 2.60 & 18.3 & 12.8 & 1 & 260.7 & 0.6 \\
7 & 28.08 .2014 & 180 & 3.17 & 18.3 & 13.7 & 2 & 370.6 & 0.9 \\
\hline
\end{tabular}


1 Table 3. Catch overview for fish species with number of individuals observed in respective bags (raised number, representing the expected escapee number 2 of the whole gear part in brackets) and codend. Average length \pm standard deviation is given combined for all upper bags, combined for all lower bags and 3 for codend. Mean values that are not sharing a letter (a, b, c) are significantly different (two-way ANOVA and post-hoc Tukey-HSD test; $\alpha \leq 0.05$ ).

\begin{tabular}{|c|c|c|c|c|c|c|c|c|c|c|c|c|c|c|c|}
\hline \multirow{3}{*}{ Species } & \multicolumn{13}{|c|}{ Individual numbers (raised to gear part) } & \multirow{2}{*}{\multicolumn{2}{|c|}{ Average size \pm SD $(\mathrm{cm})$}} \\
\hline & \multicolumn{12}{|c|}{ Collecting bags ( $\%$, the single bags represent of whole gear) } & \multirow{2}{*}{ Codend } & & \\
\hline & $1(3 \%)$ & $2(4 \%)$ & $3(3 \%)$ & $4(4 \%)$ & $5(3 \%)$ & $6(4 \%)$ & $7(3 \%)$ & $8(4 \%)$ & $9(14 \%)$ & $10(14 \%)$ & $11(15 \%)$ & $12(10 \%)$ & & Bags (up) & Bags (low) \\
\hline Brill & - & - & - & - & - & - & - & - & - & - & - & - & 6 & - & - \\
\hline Cod & - & - & - & - & - & - & - & - & - & $1(100)$ & - & $1(50)$ & 104 & - & $10.0 \pm 1.4 \mathrm{a}$ \\
\hline $\begin{array}{l}\text { Common } \\
\text { dragonet }\end{array}$ & - & - & - & - & - & - & - & - & - & $3(300)$ & - & - & 0 & - & $17.0 \pm 1.0$ \\
\hline Dab & - & $1(50)$ & - & $1(50)$ & $1(20)$ & $1(33)$ & $4(57)$ & - & - & $14(1400)$ & - & $31(1550)$ & 776 & $25.4 \pm 2.7 \mathrm{~b}$ & $12.8 \pm 4.0 \mathrm{a}$ \\
\hline $\begin{array}{c}\text { Flathead grey } \\
\text { mullet }\end{array}$ & - & - & - & - & - & $1(33)$ & - & - & - & - & - & $1(50)$ & 1 & - & $5.0 \pm 0.0$ \\
\hline Flounder & - & - & - & - & - & - & - & - & - & - & - & - & 21 & - & - \\
\hline Grey gurnard & - & - & - & $1(50)$ & - & - & - & - & - & $3(300)$ & - & $3(150)$ & 22 & - & $9.7 \pm 3.2 \mathrm{a}$ \\
\hline Haddock & - & - & - & - & - & - & - & - & - & - & - & - & 2 & - & - \\
\hline Hake & - & - & - & - & - & - & - & - & - & - & - & - & 3 & - & - \\
\hline Herring & - & - & - & - & - & - & - & - & - & - & $13(1300)$ & - & 0 & $11.0 \pm 1.0$ & - \\
\hline Lemon sole & - & $1(50)$ & - & - & - & - & - & - & - & - & - & $7(350)$ & 8 & - & $14.6 \pm 2.4 \mathrm{a}$ \\
\hline $\begin{array}{l}\text { Lesser spotted } \\
\text { dogfish }\end{array}$ & - & - & - & - & - & - & - & - & - & - & - & - & 1 & - & - \\
\hline Ling & - & - & - & - & - & - & - & - & - & - & - & - & 1 & - & - \\
\hline Long rough dab & - & - & - & - & - & - & - & - & - & - & - & - & 4 & - & - \\
\hline Mackerel & - & - & - & - & - & - & - & - & - & - & - & - & 1 & - & - \\
\hline Plaice & - & - & - & - & $6(120)$ & $5(167)$ & - & $2(67)$ & - & $5(500)$ & - & $4(200)$ & 15188 & $22.0 \pm 2.2 \mathrm{~b}$ & $12.7 \pm 4.3 \mathrm{a}$ \\
\hline Pogge & - & - & - & - & - & - & - & - & - & - & - & - & 1 & - & - \\
\hline Red gurnard & - & - & - & - & - & - & - & - & - & $1(100)$ & - & - & 394 & - & $24.0 \pm 0.0 \mathrm{a}$ \\
\hline Scaldfish & - & - & - & $1(50)$ & - & - & - & - & - & - & - & - & 0 & - & $11.0 \pm 0.0$ \\
\hline Sculpins & - & - & - & - & - & - & - & - & - & - & - & - & 4 & - & - \\
\hline Sole & - & - & - & - & - & $1(33)$ & - & - & - & - & - & - & 1 & - & $15.0 \pm 0.0$ \\
\hline Solenette & - & - & - & - & - & $1(33)$ & - & - & - & - & - & - & 0 & - & $3.0 \pm 0.0$ \\
\hline
\end{tabular}




\begin{tabular}{|c|c|c|c|c|c|c|c|c|c|c|c|c|c|c|c|}
\hline Sprat & - & - & - & - & - & - & - & - & - & - & $6(600)$ & - & 0 & $9.4 \pm 1.1$ & - \\
\hline Turbot & - & - & - & - & - & - & - & - & - & - & - & - & 1 & - & - \\
\hline Whiting & - & - & - & - & - & - & - & - & - & $1(100)$ & $2(200)$ & - & 2 & $9.5 \pm 0.7 \mathrm{a}$ & $12.0 \pm 0.0 \mathrm{a}$ \\
\hline itch flounder & - & - & - & - & - & - & - & - & - & - & - & - & 8 & - & - \\
\hline
\end{tabular}


1 Table 4. Catch overview for invertebrate species with number of individuals observed in respective bags (raised number, representing the expected escapee 2 number of the whole gear part in brackets) and codend. Average length \pm standard deviation is given combined for all upper bags, combined for all lower 3 bags and for codend. Mean values that are not sharing a letter (a, b, c) are significantly different (two-way ANOVA and post-hoc Tukey-HSD test; $\alpha \leq$ 4 0.05).

\begin{tabular}{|c|c|c|c|c|c|c|c|c|c|c|c|c|c|c|c|}
\hline \multirow{3}{*}{ Species } & \multicolumn{13}{|c|}{ Individual numbers (raised to gear part) } & \multirow{2}{*}{\multicolumn{2}{|c|}{ Average size $\pm \mathrm{SD}(\mathrm{cm})$}} \\
\hline & \multicolumn{12}{|c|}{ Collecting bags ( $\%$, the single bags represent of whole gear) } & \multirow{2}{*}{ Codend } & & \\
\hline & $1(3 \%)$ & $2(4 \%)$ & $3(3 \%)$ & $4(4 \%)$ & $5(3 \%)$ & $6(4 \%)$ & $7(3 \%)$ & $8(4 \%)$ & $9(14 \%)$ & $10(14 \%)$ & $11(15 \%)$ & $12(10 \%)$ & & Bags (up) & Bags (low) \\
\hline Brown shrimp & - & - & - & - & - & - & - & - & - & $2(200)$ & $1(100)$ & $2(100)$ & 0 & $1.1 \pm 0.0 \mathrm{~b}$ & $0.8 \pm 0.1 \mathrm{a}$ \\
\hline $\begin{array}{l}\text { Common } \\
\text { spider crab }\end{array}$ & - & - & - & - & - & - & - & - & - & $1(100)$ & - & - & 0 & - & $2.0 \pm 0.0$ \\
\hline $\begin{array}{l}\text { Common } \\
\text { starfish }\end{array}$ & - & $13(650)$ & - & $5(250)$ & - & 7 (233) & $1(14)$ & $2(67)$ & - & $20(2000)$ & - & $4(200)$ & 111 & $17.9 \pm 0.0 \mathrm{~b}$ & $10.1 \pm 2.8 \mathrm{a}$ \\
\hline $\begin{array}{l}\text { Common } \\
\text { whelk }\end{array}$ & - & - & - & - & - & - & - & $6(200)$ & - & - & - & - & 1 & - & $6.1 \pm 0.4 \mathrm{a}$ \\
\hline $\begin{array}{l}\text { Crevice } \\
\text { brittlestar }\end{array}$ & - & - & - & - & - & - & - & - & - & - & - & - & 2 & - & - \\
\hline Edible crab & - & - & - & - & - & - & - & - & - & - & - & - & 2 & - & - \\
\hline $\begin{array}{l}\text { European } \\
\text { squid }\end{array}$ & - & - & - & - & - & - & - & - & - & - & - & - & 5 & - & - \\
\hline Hermit crabs & - & $5(250)$ & - & $1(50)$ & - & $3(100)$ & - & - & - & $1(100)$ & - & - & 97 & - & $5.1 \pm 2.3 \mathrm{a}$ \\
\hline Horse mussel & - & - & - & - & - & - & - & - & - & - & - & - & 2 & - & - \\
\hline $\begin{array}{c}\text { Norway king } \\
\text { crab }\end{array}$ & - & $1(50)$ & - & - & - & - & - & - & - & - & - & - & 0 & - & $0.8 \pm 0.0$ \\
\hline Prickly cockle & - & - & - & - & - & $1(33)$ & - & - & - & - & - & - & 0 & - & $5.3 \pm 0.0$ \\
\hline $\begin{array}{l}\text { Purple heart } \\
\text { urchin }\end{array}$ & - & $1(50)$ & - & - & - & - & - & $1(33)$ & - & $10(1000)$ & - & - & 0 & - & $1.1 \pm 0.7$ \\
\hline Queen scallop & - & - & - & - & - & - & - & - & - & - & - & - & 3 & - & - \\
\hline Red whelk & - & - & - & - & - & $5(167)$ & - & - & - & - & - & - & 16 & - & $6.6 \pm 0.5 \mathrm{a}$ \\
\hline Sand star & - & $22(1100)$ & - & $4(200)$ & - & $21(700)$ & - & 13 (433) & - & $8(800)$ & - & - & 44 & - & $7.0 \pm 1.1 \mathrm{a}$ \\
\hline $\begin{array}{c}\text { Sandy } \\
\text { swimming } \\
\text { crab }\end{array}$ & - & $4(200)$ & - & $6(300)$ & - & $5(167)$ & - & $4(133)$ & - & $14(1400)$ & - & $52(2600)$ & 101 & - & $3.0 \pm 0.9 \mathrm{a}$ \\
\hline Sea anemones & - & - & - & - & - & - & - & - & - & - & - & - & 6 & - & - \\
\hline Sea mouse & - & - & - & - & - & - & - & - & - & - & - & - & 1 & - & - \\
\hline
\end{tabular}


Spiny starfish 
1 Table 5. Damage levels for invertebrate species that were observed in at least two parts following levels,

2 explained in Table 1, separated by gear part. Mean values that are not sharing a letter (a, b) are

3 significantly different (two-way ANOVA and post-hoc Tukey-HSD test; $\alpha \leq 0.05$ ).

\begin{tabular}{cccccc}
\hline \multirow{2}{*}{ Species } & \multicolumn{5}{c}{ Compartment } \\
\cline { 2 - 6 } & Inner wings & Outer wings & Belly & Extension & Codend \\
\hline Common starfish & $1.33 \mathrm{a}$ & $1.65 \mathrm{ab}$ & $1.40 \mathrm{a}$ & $3.25 \mathrm{~b}$ & $1.92 \mathrm{ab}$ \\
Sand star & $1.27 \mathrm{a}$ & $1.82 \mathrm{a}$ & $1.88 \mathrm{ab}$ & - & $2.91 \mathrm{ab}$ \\
Common whelk & - & $1.00 \mathrm{a}$ & - & - & $1.00 \mathrm{a}$ \\
Brown shrimp & - & - & $1.00 \mathrm{a}$ & $1.00 \mathrm{a}$ & - \\
Sandy swimming crab & $1.1 \mathrm{a}$ & $1.00 \mathrm{a}$ & $1.36 \mathrm{a}$ & $1.56 \mathrm{a}$ & $1.64 \mathrm{a}$ \\
Red whelk & - & $1.00 \mathrm{a}$ & - & - & $1.00 \mathrm{a}$ \\
Hermit crabs & $1.33 \mathrm{a}$ & $1.00 \mathrm{a}$ & $1.00 \mathrm{a}$ & - & $1.21 \mathrm{a}$ \\
Sponges & $3.00 \mathrm{a}$ & - & - & - & $3.00 \mathrm{a}$ \\
Purple heart urchin & $1.00 \mathrm{a}$ & $1.00 \mathrm{a}$ & $1.00 \mathrm{a}$ & - & - \\
\hline
\end{tabular}

4 


\section{Supplementary material}

2 Table S1. Fish species observed within the study.

\begin{tabular}{cc}
\hline Species & Scientific name \\
\hline Brill & Scophthalmus rhombus \\
Cod & Gadus morhua \\
Common dab & Limanda limanda \\
Common dragonet & Callionymus lyra \\
Flathead grey mullet & Mugil cephalus \\
Flounder & Platichthys flesus \\
Grey gurnard & Eutrigla gurnardus \\
Haddock & Melanogrammus aeglefinus \\
Hake & Merluccius merluccius \\
Herring & Clupea harengus \\
Lemon sole & Microstomus kitt \\
Lesser spotted dogfish & Scyliorhinus canicula \\
Ling & Molva molva \\
Long rough dab & Hippoglossoides platessoides \\
Mackerel & Scomber scombrus \\
Plaice & Pleuronectes platessa \\
Pogge & Agonus cataphractus \\
Red gurnard & Chelidonichthys lucernus \\
Scaldfish & Arnoglossus laterna \\
Sculpins & Myoxocephalus spp. \\
Sole & Solea solea \\
Solenette & Buglossidium luteum \\
Sprat & Sprattus sprattus \\
Turbot & Psetta maxima \\
Whiting & Merlangius merlangus \\
Witch flounder & Glyptocephalus cynoglossus \\
\hline & \\
\hline &
\end{tabular}

3 